\title{
QUALITATIVE RESULTS FOR SOLUTIONS TO NONLINEAR CAPUTO DIFFERENTIAL EQUATIONS SATISFYING THE OSGOOD CONDITION
}

\author{
M. Palani, C. C. Tisdell and A. UsacheV
}

\begin{abstract}
We consider an initial value problem involving a single-term Caputo fractional differential equation. For those with right-hand sides that satisfy the Osgood condition, we establish novel uniqueness and comparison theorems.

In addition, we discuss a reduction of the fractional order problem to an integer ordered one. We identify inconsistencies in recent work by Demirci and Ozalp regarding this via the use of several counterexamples. Nevertheless, we take a constructive approach by proving that $a$ priori estimates for the solution of a fractional order problem can be obtained from that for the corresponding integer order problem. All results are illustrated with examples.
\end{abstract}

Mathematics subject classification (2010): 34A08, 34A12, 26A33.

Keywords and phrases: Caputo derivative, Osgood condition, existence of solution, comparison theorem.

\section{REFERENCES}

[1] M. Abramowitz And I. A. Stegun (Eds), Handbook of Mathematical Functions with Formulas, Graphs, and Mathematical Tables, National Bureau of Standards, Applied Mathematics Series 55, 9th printing, Washington, 1970.

[2] R. P. Agarwal and V. Lakshmikantham, Uniqueness and nonuniqueness criteria for ordinary differential equations, Series in Real Analysis, 6. World Scientific Publishing Co., Inc., River Edge, NJ, 1993.

[3] E. DemiRCi AND N. OzALP, A method for solving differential equations of fractional order, J. Comput. Appl. Math. 236, 11 (2012), 2754-2762.

[4] J. DENG AND L. MA, Existence and uniqueness of solutions of initial value problems for nonlinear fractional differential equations, Appl. Math. Lett. 23, 6 (2010), 676-680.

[5] K. Diethelm, The mean value theorems and a Nagumo-type uniqueness theorem for Caputo's fractional calculus, Fract. Calc. Appl. Anal. 15, 2 (2012), 304-313.

[6] K. Diethelm And N. J. Ford, Analysis of fractional differential equations, J. Math. Anal. Appl. 265 (2002), 229-248.

[7] A. Kilbas AND S. MaRZAn, Nonlinear differential equations with the Caputo fractional derivative in the space of continuously differentiable functions, Differ. Equ. 41, 1 (2005), 84-89.

[8] A. Kilbas, H. SRivastava And J. Trujillo, Theory and applications of fractional differential equations, North-Holland Mathematics Studies, 204. Elsevier Science B. V., Amsterdam, 2006.

[9] V. LAKShmikANTHAM AND A. S. VATSALA, General uniqueness and monotone iterative technique for fractional differential equations, Appl. Math. Lett. 21, 8 (2008), 828-834.

[10] V. Lakshmikantham, S. Leela, And D. J. Vasundhara, Theory of Fractional Dynamic Systems, Cambridge Scientific Publishers, 2009.

[11] W. F. OsGOoD, Beweis der Existenz einer Lösung der Differentialgleichung $\frac{d y}{d x}=f(x, y)$ ohne Hinzunahme der Cauchy-Lipschitz'schen Bedingung, Monatsh. f. Mathematik und Physik 9, 331 (1898), 331-345.

[12] C. C. TISDELL, On the application of sequential and fixed-point methods to fractional differential equations of arbitrary order, J. Integral Equations Appl. 24, 2 (2012), 283-319. 
[13] Chris Tisdell, What is a Lipschitz condition?, Dr Chris Tisdell's YouTube Channel, 14/02/2012, accessed 17/01/2017, www . youtube. com/watch?v=Cnc83B3C2pY.

[14] C. C. TisDeLL, Maximal solutions to fractional differential equations, Fract. Differ. Calc. 5, 1 (2015), $79-85$. 